\title{
Development of biomechanical measures to assist in the prediction of early progression in idiopathic scoliosis
}

\author{
Karl Zabjek, R Zeller \\ From 7th International Conference on Conservative Management of Spinal Deformities \\ Montreal, Canada. 20-22 May 2010
}

Idiopathic scoliosis (IS) is a class of paediatric spinal deformities that has historically posed a significant challenge to the orthopaedic and scientific community. Our understanding of the underlying mechanisms associated with the early progression to advanced stages that require surgical intervention is limited. Current clinical models of assessment provide limited insight into the biomechanical and neuromuscular factors that contribute to the alignment and stability of the spine. There is an emerging recognition that new insight into the factors that affect spinal stability and the progression of a spinal deformity may be gained by expanding current observational techniques beyond the clinic. Technological innovations and advancements in analytical techniques have provided a unique opportunity to develop measurements of neuromuscular function and spinal stability. The overall aim of our present work is to develop new biomechanical measures that will provide insight into the factors that contribute to the early progression of IS. The first specific aim of this pilot project is to further develop a technique that will provide a localized estimate of the asymmetric positioning of the Centre of Mass (COM) in relation to the underlying skeletal structures of the pelvis (sacrum) and spine (apex of spinal curvature). The second specific aim is to determine the association between these measures with persistent asymmetric posture and muscle activation patterns during the performance of dynamic activities that are typical of every day life. To achieve these objectives we are currently developing a mixed methods approach that includes the coupling of a radiological, biomechanical and ambulatory monitoring assessment.

University of Toronto, Toronto, Canada

Full list of author information is available at the end of the article
This includes a 3D assessment of the spine utilizing EOS to characterize the spinal deformity, and a dynamic assessment that is focused on characterizing the dynamic patterns of muscle activity and movement. This latter component of the project involves an in laboratory biomechanical assessment with a multiple camera Vicon and 16 channel EMG system, and an out of lab ambulatory monitoring assessment. This initial study will provide the foundation to conduct future work focused on identifying new biomechanical factors that are positively associated with the early progression of IS.

Published: 10 September 2010

doi:10.1186/1748-7161-5-S1-O35

Cite this article as: Zabjek and Zeller: Development of biomechanical measures to assist in the prediction of early progression in idiopathic scoliosis. Scoliosis 2010 5(Suppl 1):035.

Submit your next manuscript to BioMed Central and take full advantage of:

- Convenient online submission

- Thorough peer review

- No space constraints or color figure charges

- Immediate publication on acceptance

- Inclusion in PubMed, CAS, Scopus and Google Scholar

- Research which is freely available for redistribution

Submit your manuscript at www.biomedcentral.com/submit 